A VISIT TO "JESUS HILFE" OR THE LEPROUS HOSPITAL OF JERUSALEM.

JACOB E. SCHADLE, M.D. Clinical Professor of Laryngology in the University of

ST. PAUL, MINN.

During a recent visit to Palestine it was my pleasure to inquire into the condition of the lepers of that country and pay a visit to the "Jesus Hilfe" Asylum. Through the courtesy of our American consul, I was most cordially received by the superintendent and physician in charge, Dr. Einsler, and conducted through the institution. Every available opportunity was given me to study the disease with a view of bringing home to the profession of Minnesota, where the affection at present exists, some information as to its prevalence in the Orient, where from time immemorial, so to speak, it has had its home.

Notwithstanding the fact that "Jesus Hilfe" Hospital is one of the best equipped of its kind in the world, and is an imposing stone building surrounded by luxuriantly blooming gardens, the average tourist is content to view it from a distance. In fact, it is somewhat difficult to secure the services of a dragoman who is willing to cross its threshold. The hospital is situated in the German settlement of Jerusalem, on the hillside, in full view from the main road leading to Bethlehem, probably a half hour's drive from Jerusalem, and commands a fine view of the surrounding country. the management of the Brotherhood, and it has since become their absolute property.

\section{MANAGEMENT OF THE HOSPITAL.}

'The Chapter House of the Brotherhood, under whose control the hospital is, is in the Kingdom of Saxony. They appoint the house parents and four deaconnesses who are trained nurses, and publish annually a statement of the disposition of the moneys received. A local committee composed of members of the German Iutheran congregation of Jerusalem has the immediate supervision of the institution. Moșt gratifying results have been obtained.

\section{THE HOSPITAL INMATES.}

Fifty patients can be accommodated and the hospital is sometimes taxed to its utmost capacity. On account of local prejudices, when a shelter was first provided, it was difficult to induce lepers to enter the hospital, but before the old building was abandoned twenty patients were enrolled. Unfortunately these poor creatures can only be carefully nursed and made comfortable until death ends their misery, as a cure for this loathsome disease remains still undiscovered.

Those who become inmates have their sores bandaged daily, are frequently bathed, furnished with comfortable clothing, fresh linen and nourishing food, besides being provided with space in the ward, in which are a bed, an easy chair and combination table and cupboard. They are not compelled to remain in the hospital for

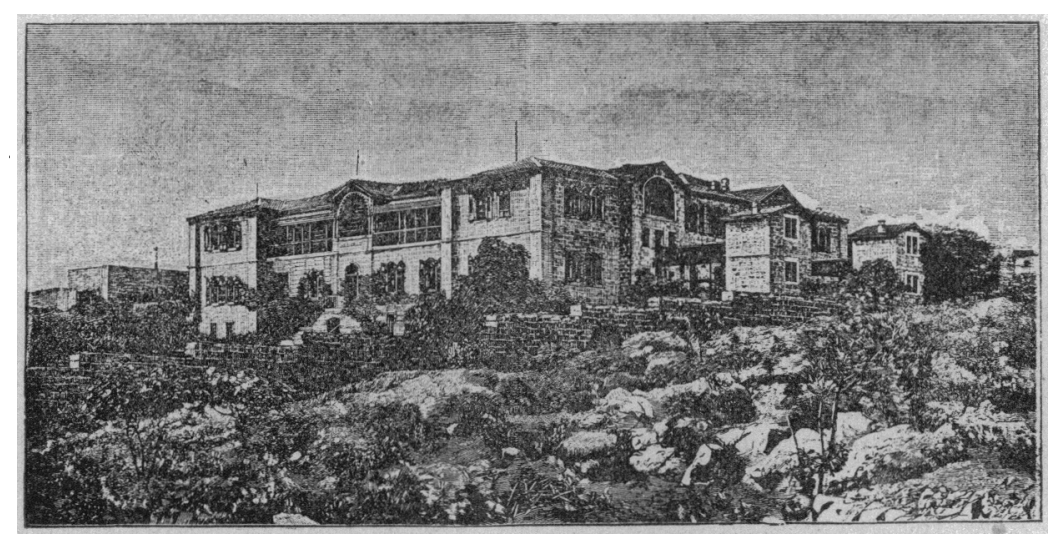

Fig. 1.-Jesus Hilfe Hospital.

The history of its origin and growth breathes the true missionary spirit, a brief account of which may be interesting.

ORIGIN AND GROWTH OF THE HOSPITAL.

In the year 1865, a Pomeranian baroness, von Keppenbrück, visited Palestine, and being deeply impressed with the wretchedness and misery of the lepers, made a liberal contribution toward the founding of an asylum for them. Working in conjunction with the order of the Evangelical Brotherhood, additional funds were obtained in England. A committee was appointed and a building ereeted near the Jaffa Gate, where lepers who came of their own volition were admitted. Years later, however, it was found that the building was inadequate to accommodate all who applied for admission, therefore plans were effected to erect the present hospital. Voluntary contributions were received from Germany, England, Switzerland and North America. In 1887 it was completed, and the inmates were transferred to the new building. A few years prior to this, however, the founder of this magnificent charity placed it under any given time, but as a rule they soon appreciate their improved environment and become attached to those who care for them and contribute to their comfort. They are not permitted to leave the grounds, beg or marry; neither are married lepers admitted. Through the house father they keep in touch with their friends, and at certain times are permitted to receive them. On pleasant days they sit about in the garden or on the roadside outside the entrance gate, amusing themselves playing draughts or other games.

Those having use of their hands and feet assist in the work about the grounds. Reading is a favorite pastime, and being read aloud to is considered a privilege. Mental obtuseness is not of necessity present to the extent that was formerly supposed. They are said to evince a keen interest in any occurrence out of the ordinary routine of every day life in the hospital, such as the return of an attendant after a vacation, and gladly contribute their best to the "welcome home," dancing the fantasia, etc., and for days talking of nothing but the coming event. 
LEPROSY IN PALESTINE.

'The number of lepers in Palestine is about four hundred, the village of Siloam, southeast of Jerusalem, alone having between thirty and forty. The government designates places for them in which to live, as they are excluded from social and family life. Institutions under Mohammedan jurisdiction accord them full liberty to wander about at will. They sit along the wayside singly or in groups, asking alms. The roads frequented by tourists are their favorite resorts, a large proportion of the Siloam contingency congregating at the foot of the hill leading to the Garden of Gethsemane and the Mount of Olives. Several of the accompanying photographs were taken from these groups. Since 1893 a residence has been set apart for children, the offspring of lepers, in which are a half dozen or more healthy boys and girls. It is hoped that in this way such offspring can be protected against the development and ravages of the disease by good care, proper training and nourishing food. The majority of lepers manage to eke out an existence by begging, and prefer their

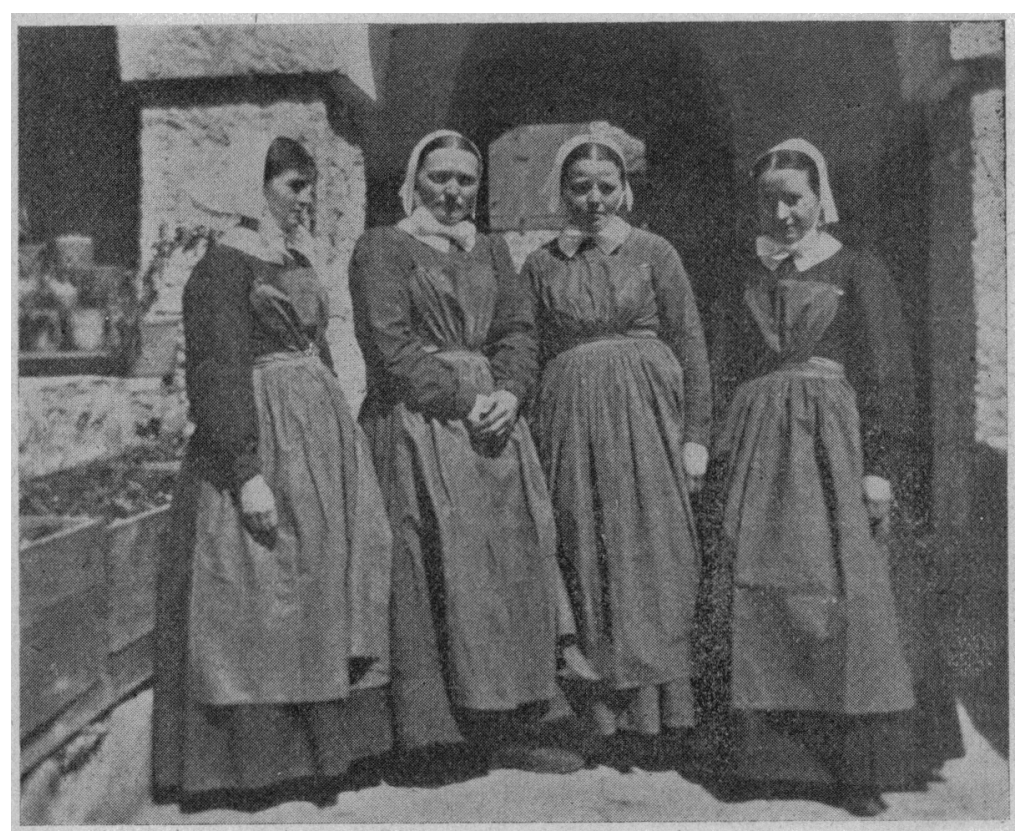

Fig. 2.-Deaconesses

independence and alms to a residence in an asylum. 'The fact that their condition is aggravated by this inode. of life, neglect and filth is self-evident, and beyond the appreciation of the average Oriental, who is content to habitually sleep on a heap of rags or a bundle of straw with perhaps nothing but a stone for a pillow and is oftener without than with a covering, shedding his garments only when in tatters. A beggar society was some years ago founded in Jerusalem among the lepers, with a president at its head, called a "sheik." Every leper who desires to become a member must pay an initiation fee with the promise to beg and contribute a certain portion of his income obtained in this way to the general fund of the society. Individuals who have no money or are too ill to beg are not accepted.

\section{IAPROSY INVESTIGATIONS.}

Dr. Einsler, the physician in charge of the hospital, is a Hungarian by birth, and about fifty years of age. For a period of sixteen years he has been identified with the asylum and is enthusiastically in love with his work. He is a keen observer and fully abreast of the times, devoting himself unceasingly to his laboratory, and prosecuting researches with a view to throw more light on the mooted questions of leprosy. It was my pleasure and privilege to have several personal interviews with Dr. Einsler regarding his long experience with the disease. He spoke of the mental and physical characteristics of lepers, and especially dwelt on the clinical aspects of the disease as it presents itself in Palestine. He holds the view that as yet it is not definitely known how leprosy is propagated, whether through heredity, contagion or infection, but he excludes contagion for the reason that no case has ever come under his observation that would lead him to believe in the theory, basing his opinion at the same time on the fact that people constantly mingle with lepers. Then, too, lepers always have been and are still allowed to wander through the streets or along the highway, transacting business, handling money, fruit, etc. He believes a peculiar susceptibility or predisposition exists primarily, and that heredity or infection plays its part afterward. And still, on this point he is not satisfied, because as yet the facts in his possession are not fully established, but he hopes that as bacteriologic investigations progress something more definite will eventually be ascertained. The lepra bacillus has been discovered and is now generally recognized as a special micro-organism giving rise to the malady.

I am able to show under the microscope a preparation quite characteristically demonstrating this bacillus, which was mounted in the "Jesus Hilfe" Hospital, the specimen having been taken from a pustular nodule on the face of a patient. Dr. Einsler belicves that as soon as cultures are made and inoculations performed our information on the manner of communication will be more definite and the question will become settled. In his laboratory scientific investigations along this line are being made, and before long, he thinks, he will be able to publish tangible conclusions on the subject. In speaking of the usual early manifestations of leprosy, he said that the upper respiratory tract-the mucous membrane of the nose and throat-becomes affected. The turbinated bodies, the cartilages of the nose, the soft palate and the larynx are attacked. It is with considerable interest that I note this observation, because it concerns us who are specially engaged in the treatment of the diseases of the nose and throat.

The forms of leprosy as observed in Palestine are the nodular, nervous, and the mixed.

\section{CLINICAI, FEATURES.}

'The skin and the respiratory mucous membrant become affected. The face, the hands, the forearms, the ankles and the feet not unfrequently evidence the onset of the disorder. The skin is at first dry and glossy, while later appear small lumps or nodules, either in great or small numbers, which increase but little in size and often remain unchanged for years. This sondition is called the small nodular variety of leprosy. Then again only a few nodules appear, about the size of a hazlenut. Frequently in this form there is present an intensely red discoloration or inflammation of the skin, resembling erysinelas or inflammation of the lymph vessels. Sometimes this condition is: 
accompanied by a marked elevation of the body temperature, which continues for several days and is followed by an increase of the number of nodules. The discoloration of the skin does not limit itself to the nodules, but also involves the surrounding integument. It is not unusual for the nodules to degenerate when fever is present, which condition may be accompanied by a diffuse swelling and infiltration of the neighboring tissues.

The broken-down nodules generally heal and cicatrize, but, on the other hand, they may become associated in the necrotic process with others lying in the same region, in this way forming extensive suppurative areas which show no disposition to heal, thus eventually exhausting the vitality of the patient and causing death. It not seldom occurs that the nodular forms of the disease are both present in the same individual; so apparent is this that no trouble is experienced in determining their co-existence. Palpation is invaluable, because not infrequently the sense of touch is the only means by which to determine the presence of the small nodules, while the large ones are visible. There are instances where no nodules exist and nothing is to be seen but circumscribed thickenings of the skin, giving the characteristic appearance of leprous spots. Sometimes, owing to the existence of these circumscribed areas, the sweat glands perish and lose their function, thus giving rise to dryness of the skin. Those parts of the body covered with hair undergo a similar change, the hair bulbs degenerate, followed by dryness, brittleness and dropping out of the hair, eventually leaving behind a smooth, shiny surface. Examples were cited where the eyebrows or even the beard had thus suffered. At no time has it been observed that the hair covering a leprous skin has turned white.

Somewhat in a similar manner as that of the skin, the mucous membrane of the mouth, nose and eyes suffers. Nodules appearing on mucous surfaces are generally paler in color than the tissue adjacent to them. Mucous membrane nodules degenerate more easily than those appearing on the skin, a circumstance which is not quite understood. The fact perhaps is due to the nature of the irritant and the susceptibility of the membrane. Probably the character of the local irritant makes the difference. Yet it can not be disputed that the same morbid process is at work in the mucous membrane as in the skin.

Circumscribed swellings or thickenings are also characteristic of the mucous membrane. When these areas of acute swellings join similarly affected nodules lying in the same region, extension of the morbid process takes place and considerable destruction of tissue results. In grave cases the cartilages of the nose and the soft palate are destroyed. Extensive destruction of the palate usually forms a direct communication between the mouth and nose. The mucous lining of the posterior nares, nasopharynx and larynx mav also be invaded by the bacillus of leprosv. When the larynx is affected, hoarseness and sometimes complete loss of voice are produced.

The tongue is not exempt. Frequently nodules appear in great numbers, whereby the tongue becomes thickened, uneven or fissured. In certain instances the gums swell and bleed as in scurvy. The teeth loosen, drop out or are easily removed. The eyes not infrequently become involved. The nodules appear on the upper surface or on the edges of the lids. Movement of the lids is interfered with and the fissure between the lids becomes contracted. Nodules seldom appear on the mucous membrane of the lids, while the mucous membrane of the orbit is frequently affected. The cornea is rarely involved. Generally the conjunctivæ are dry and brilliantly white. By and by there takes place a diminution of the luster of the sclerotic coat, which is gradually and surely followed by total blindness. Small nodules form at the edges of the sclerotic coat, forming, as it were, flaps of the mucous membrane.

The disease is not limited to the skin and mucous membrane; the lymph glands may become involved. The glands of the neck swell and inflame. Sometimes glandular suppuration takes place and gives origin to a continued discharge of pus.

Regarding the first stage of the nervous form of

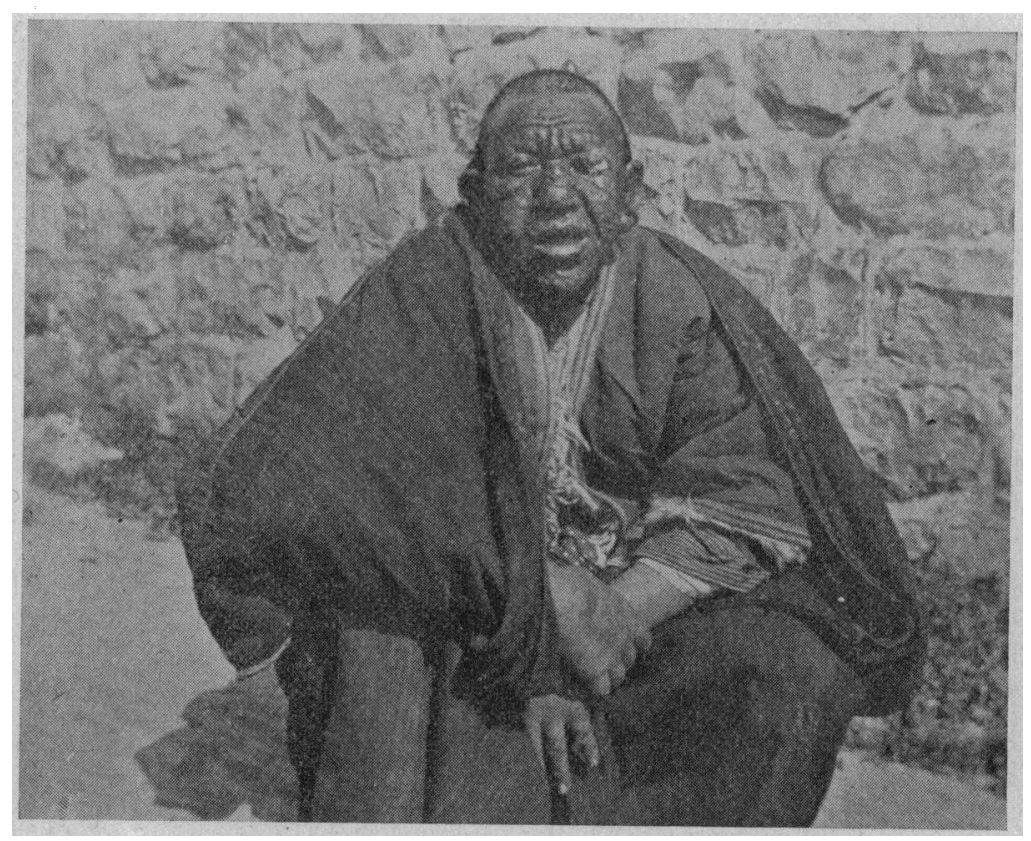

Fig. 3.-Lepra Leontiasis.

leprosy not much is known, because the individual seldom comes under the observation of the physician until long after the nervous system has shown signs of disturbance. It is only after the nervous affection has advanced that attention is drawn to it. The beginning period of the nervous form is characterized by spots appearing on the skin, accompanied by fever. Violent pains of the extremities, resembling more or less those of rheumatism, is a frequent symptom.

Extreme sensitiveness of the skin exists. The advanced stage of the nervous form is not marked by a change of the surface of the skin, except that now and then increased pigmentation is apparent and sensation is usually decreased. As the nervous affection progresses, sensitiveness diminishes, especially in the face and the extremities, which condition increases until entire loss of sensation is experienced or anesthesia of the parts is established. But even when anesthesia of the skin is present, the deeper structures are still sensitive to pain. In some cases the peripheral nerves assume spindle-formed thickenings. Amputations some- 
times are rendered possible in consequence of the anesthesia and a general anesthetic is not needed. The incision of the skin is unaccompanied by pain, but on the other hand, separation of the decper layers of tissue is atterded by violent pain.

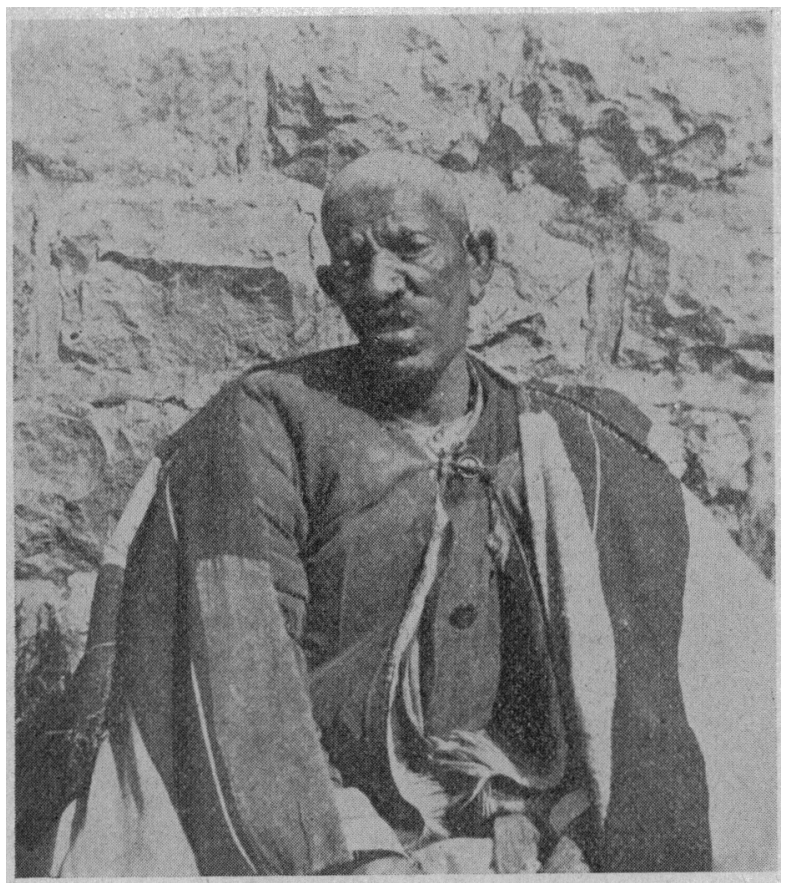

Fig. 4.-A nesthetic Faclal Leprosy.

The muscles undergo certain changes. Their tendency is to grow smaller in circumference, but they do not disappear. It is apparent, not true atrophy. The muscles of the face, the hands and the feet undergo

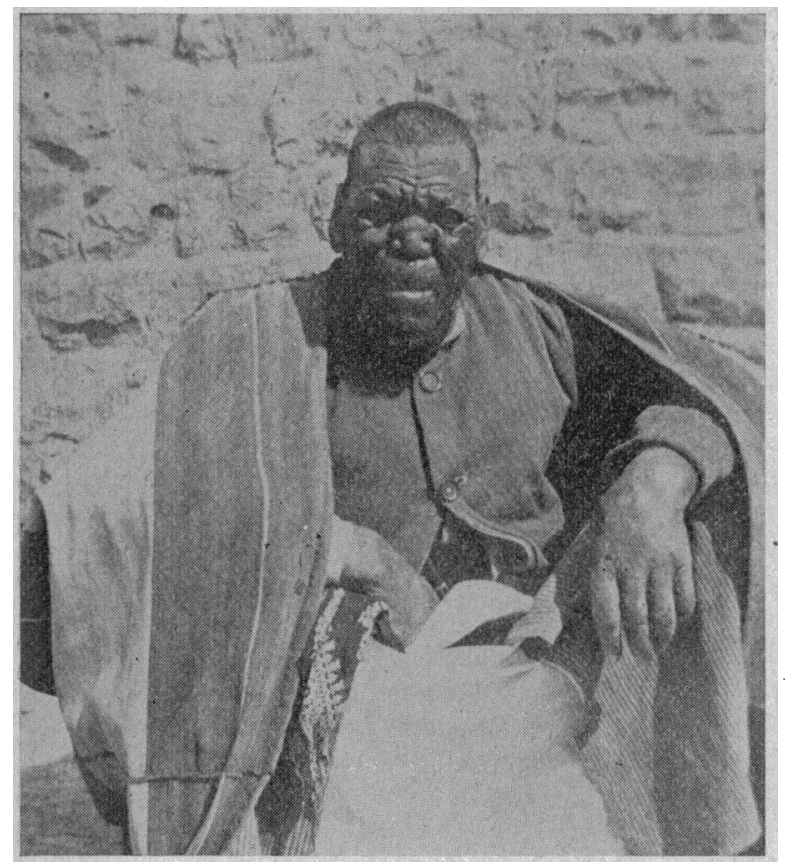

Fig. 5.-Lepra Leontiasis.

the atrophic process. The face assumes a peculiar, staring countenance, expression being entirely lost. The eyes can not always be closed, or only partially so, in consequence of which, through mechanical influences, serious trouble may arise, often inducing complete blindness. 'The muscles of the palms of the hands and of the soles of the feet do not atrophy.

Motility of the fingers and toes diminishes. Owing to the predominating strength of the contracting muscles, the fingers and toes contract or become clutched.

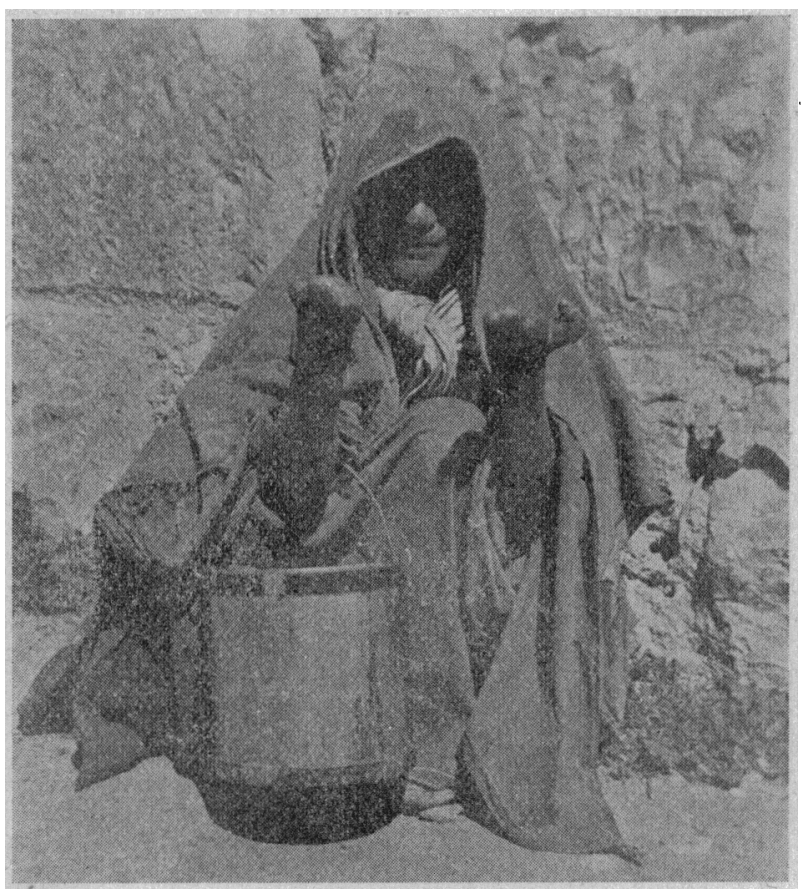

Fig. 6.-A so-called Healed Leper. Natural Process.

In the course of the discase the joints become affected and the loss of a finger or a hand follows. An illustration of this is seen in the photographs. The causc of the natural amputation, as it were, is explained as follows: Channel-like swellings form in the neighborhood of the

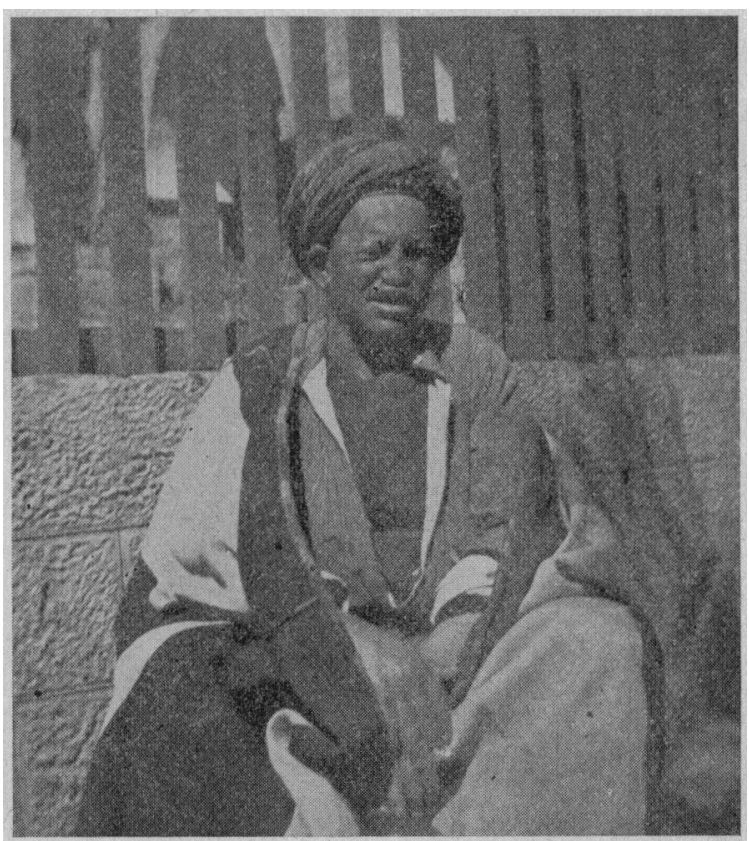

Fig. 7.-Early Stage of Leprosy of the Face.

joint, which begin externally and gradually extend deeper and deeper until the joint is destroyed and the member drops off, healing and cicatrization ensuing. This method of exfoliation is peculiar to the fingers and toes. Then again, inflammation of the joint, attended 
by violent pains and fever, followed by suppuration and necrosis of the bone and final dropping off of the limb, is the case, in which instance healing, cicatrization and the formation of a stump take place.

Another form is periostitis of the bone of a finger, hand, toe or foot, whereby tumors, abscesses and sinuses form. By means of a sound, necrosis is usually detected. The suppurative tumor remains open until the diseased bone disappears, healing afterward following. The development of this form of leprosy differs in different individuals. Many of the patients remain apparently the same for years, because the atrophy and contraction of the muscles progress slowly. Therefore such a one goes for many years with contracted fingers and toes. On the other hand, when ulcerative processes are present, exfoliation often is speedily accomplished.

When the toes are severely contracted the patient is compelled to walk on the tips of the toes. In spite of the reduced sensitiveness of the parts, the leper may plead for amputation of the affected member. Accidents sometimes befall a leper suffering from the nerv- features of leprosy as it exists in Palestine, with the clinical account given by Dr. Hansen, the discoverer of the lepra bacillus, I find the general characteristics of leprosy in northern Europe accord with those peculiar to lepers of the Orient.

Permission was granted to take pictures of some of the inmates whose appearance, condition and history appealed to me as being exceptionally instructive. They convey a quite clear idea of the different forms of leprosy, especially the nodular varieties. , With the aid of an interpreter brief histories were developed, an account of which $I$ append.

DESCRIPTION OF ILLUSTRATIONS.

Fig. 1 is a picture of the "Jesus Hilfe" Hospital, giving a good idea of its location and architectural design.

Fig. 2 is representative of the four Moravian deaconesses who so faithfully nurse the lepers of the institution. They are intelligent, and thoroughly devoted to their life-work.

In conversation with the deaconesses in regard to

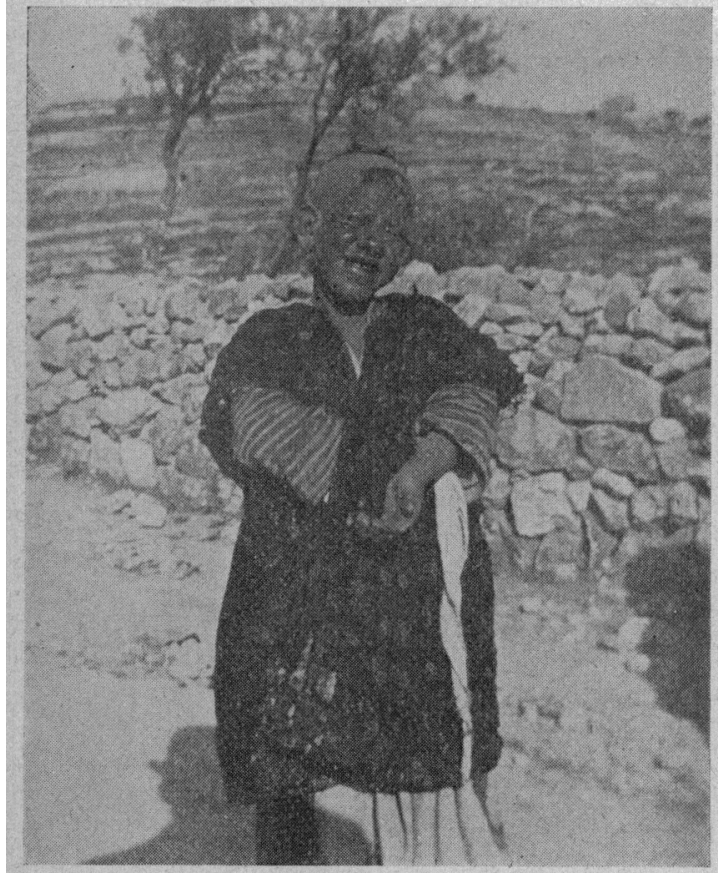

Fig. 8,-A Leprous Beggar Boy. Mount of Olives in Background.

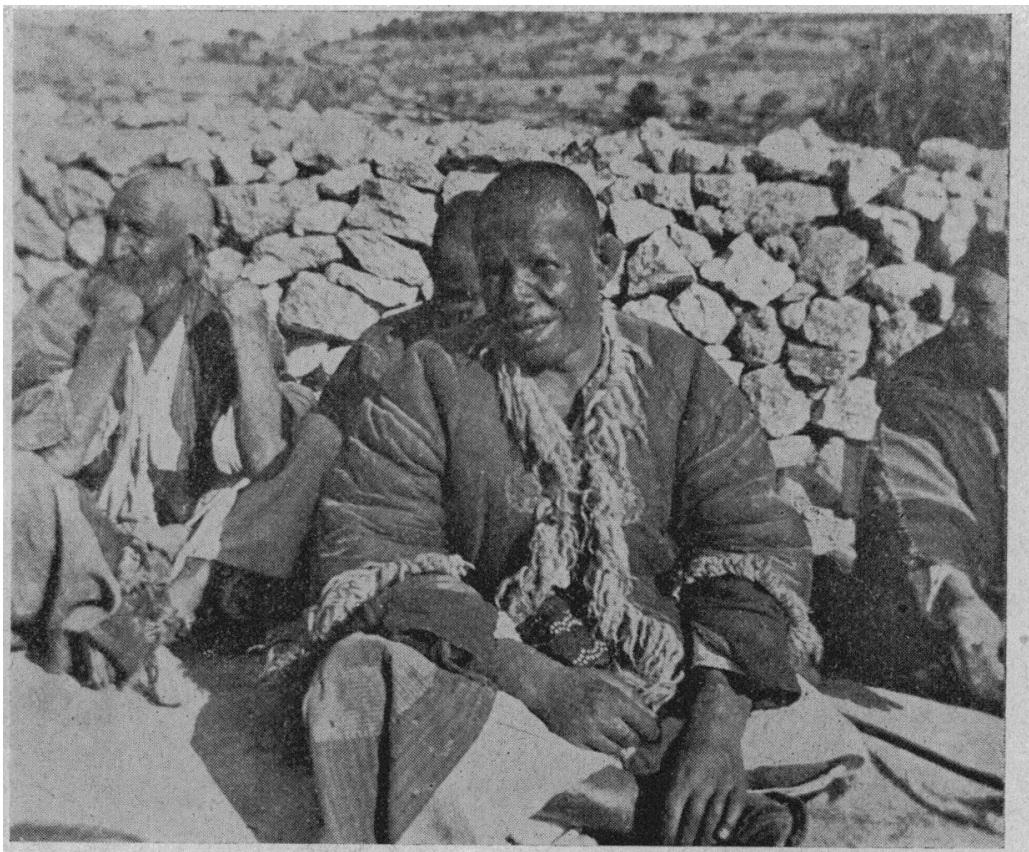

Fig. 9.--A Group of Lepers Along the Highway. ous or anesthetic variety of the disease. Incidents were related where the patient when reclining toward heated bodies became severely burned. The accident is often followed by marked sloughing of the parts and the formation of disagreeable cicatrices. Sometimes cases of burning arise where the leper is not conscious of the injury inflicted, the accident being recognized only by some one near the patient, through the detection of the odor of the burning tissue.

\section{TREATMENT OF LEPROSY.}

Respecting the treatment of leprosy, no specific is as yet known. All that it is possible to do is to make the patient comfortable. The average duration of life is about forty years. Some lepers live to be quite old, while others succumb to the disorder early. Extermination of the disease can only be brought about by confinement in hospitals and the intervention of marriage. COMMENTS.

In comparing the results of my personal interview with Dr. Einsler regarding the behavior and clinical their personal experiences with the lepers, I was deeply impressed by their zealous devotion to the patients and the risk of infection they were taking. But it seems they do not fear infection; they go about among the patients most courageously, performing the duties assigned them. They are in daily contact with the lepers. handling them, washing their clothes and dressing their sores. No case of leprosy has as yet arisen among them. Of the four now in the hospital, one has been employed thirteen years, one ten, one five, and the fourth. one year.

Fig. 3 represents a man aged 30 years who has been suffering from leprosy for a period of three years. The disease first made its appearance on the face. One of the early symptoms was pain and unusual dryness of the nose, followed by external redness of the face when exposed to the sun, the discoloration later developing into purplish red. Nodules then appeared, no other part of the body at this time having been affected. Tho man is not married. So far as he knows leprosy did 
not exist in the family, nor does he know how he contracted the disease.

When I saw him the forearms and the lower extremities showed an eruption, the eyes and arms were anesthetic, but motion was not interfered with. 'The patient weighs 160 pounds, sleeps well, has no appetite and complains of more or less urinary and alimentary dis-

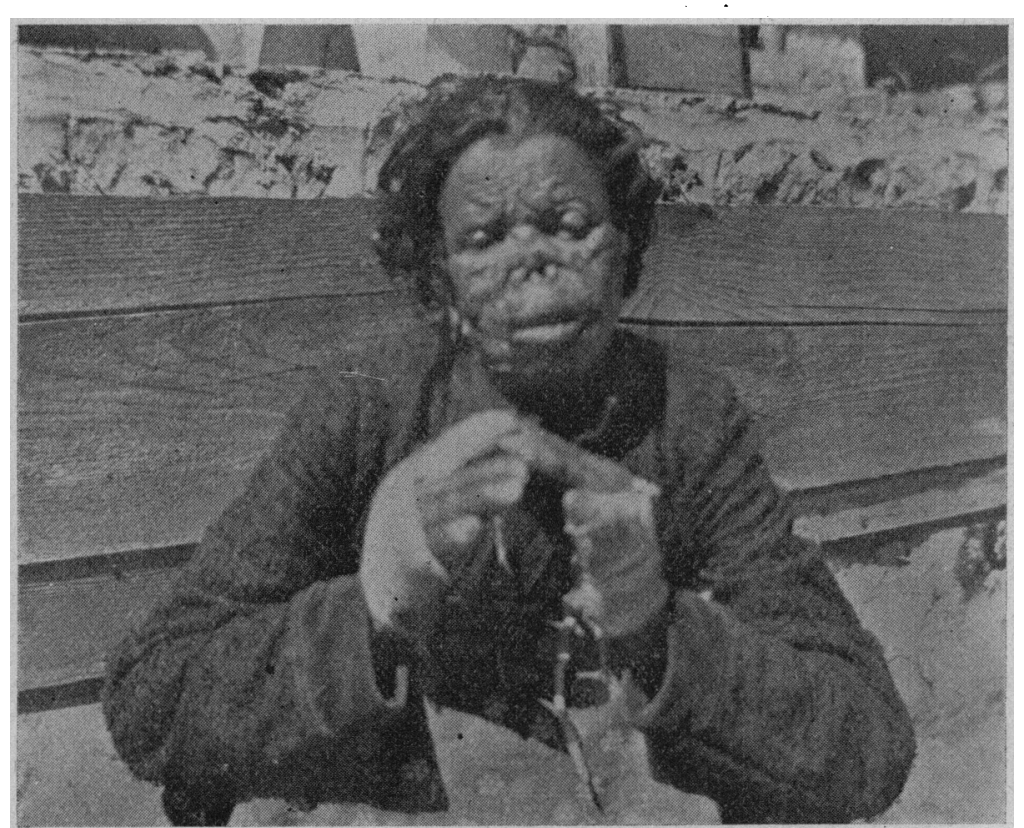

Fig. 10.-Advanced Form of Leprosy.

turbance. T'wo tumors the size of English walnuts presented under the lobes of the ears, the left one being quite visible in the photograph. 'These tumors appeared one year ago. At the commencement of the disease impaired hearing was noted, but since the affection has become fully established the patient thinks the hearing has improved.

The left eye is affected. The eyelids are nodular, thus causing stiffness and a difficulty in closing them. Complaint is made of obstruction of the nose, which organ at present, externally, is nodular and purplishred. In consequence of the intensely diffused infiltration and cicatricial tissue. the nose presents a broad and deformed aspect. Nose-bleed and hemorrhages from the mouth and throat are common occurrences. Soon after the first manifestations of the disease, soreness of the mouth and throat was complained of and caused considerable annoyance. At present the voice is very much impaired, complete aphonia sometimes being the case. Deglutition is difficult.

His face is almost black, or of a deep purple hue, covered extensively with nodules varying from the size of a grain of wheat to that of a small hazlenut. The nose, as has been noted, is thick, broad and nodular, while the upper and the lower extremities are covered with cicatrices. The hair, it will be observed, has disappeared from the eyebrows. The left eye shows the existence of an ulcer along the outer canthus. The upper and lower lips are both invaded by the disease, as is shown by their thickness, evidencing extensive infiltration of their structures. The hands and fingers are infiltrated and thickened. 'The case is typical of nodular leprosy.

Fig. 4 represents a man, also 30 years of age. $\mathrm{He}$ is married, but his wifo left him on account of his loathesome disease. He has no children, and his wife is not affected. He declares no trace of the disease is to be found in his family. He has been ill for six year: and has had sore throat for three.

Unlike the previously described case, this man does not show so characteristically the evidences of leprosy in the face. What is most striking in his condition is the extreme involvement of the upper respiratory tract. His roice is entirely gone and he is enabled only to speak in whispered tones which are imperfectly enunciated and difficult to understand.

The disease of the air-passages is rapidly growing worse. Sleep is much interfered with, owing to impeded respiration. When lying down, he says: "I feel like a dead man." The nose is deformed and obstructed, with pain in the eyes and face. The hearing is unimpaired, his eyes sore, the sight of the right one being affected. The soft palate, on inspection, was found to be entirely destroyed and the larynx was undergoing destructive changes. The right foot is nodular and anesthetic. His arms are affected in the same manner. He complains of poor appetite and intestinal disturbances. The patient is losing ground rapidly and is expected to die soon.

Fig. 5 is representative of a leper, 35 year's of age. Leprosy attacked him five years ago, since which time the disease has been running a rather rapid course. It first appeared below the knee of the right leg, and afterward extended up toward the thigh. The second year of the malady the left leg became sim-

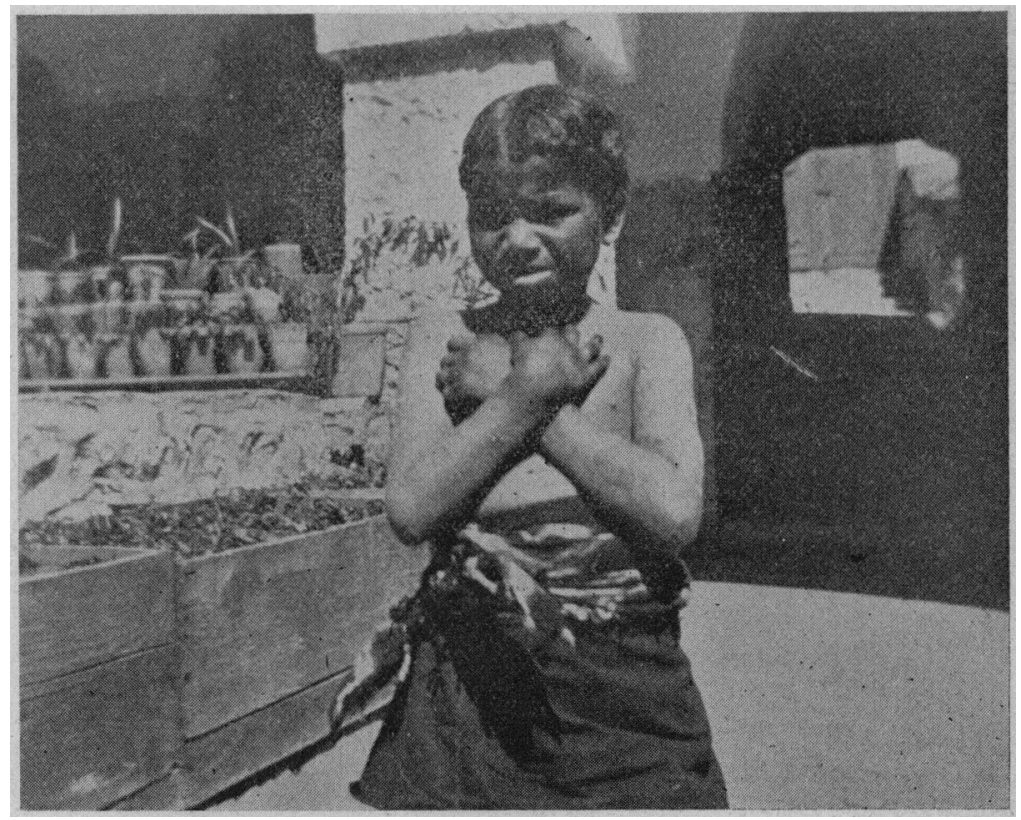

Fig. 11.- Warly Period of Ieprosy

ilarly affected. At first, pain in the legs was a pronounced symptom, while later on anesthesia of the legs became manifest. Now pain and anesthesia seem to alternate. Two and a half years ago the nose became involved, characterized by nose-bleed and expulsion of 
ulcerative products. Inspection of the patient, as well as of the photograph, reveals the fact that the nose has suffered materially. Deformity is present in consequence of a total loss of the triangular cartilage of the septum narium, thus giving rise io the depressed or brokendown state of the point of the nose. The man experiences trouble in swallowing and says he has had hemorrhages from the nose and throat. It will be noticed that the skin of the face and of the hands is thickened and infiltrated. Examination of the lower extremities showed the effects of leprous ulcerations.

Fig. 6 represents a leper beggar whose picture wils is introduced to demonstrate the early facial manifestations of the disease. Obsertation of the face shows the period of infiltration and discoloration of the skin without, as yet, nodular formations. Under bright sunlight this man's face turned a bright purplish-red.

Fig. 8 is illusirative of a leprous beggar boy 8 years old, who stands ready to receive alms, as is indicated by his outstretched hand. $\mathrm{He}$ is still in the early stage of leprosy, which is a family complaint, his mother having had it. Evidences of the disease became manifest two years previously, on the face, which on close inspection of the picture reveals the fact.

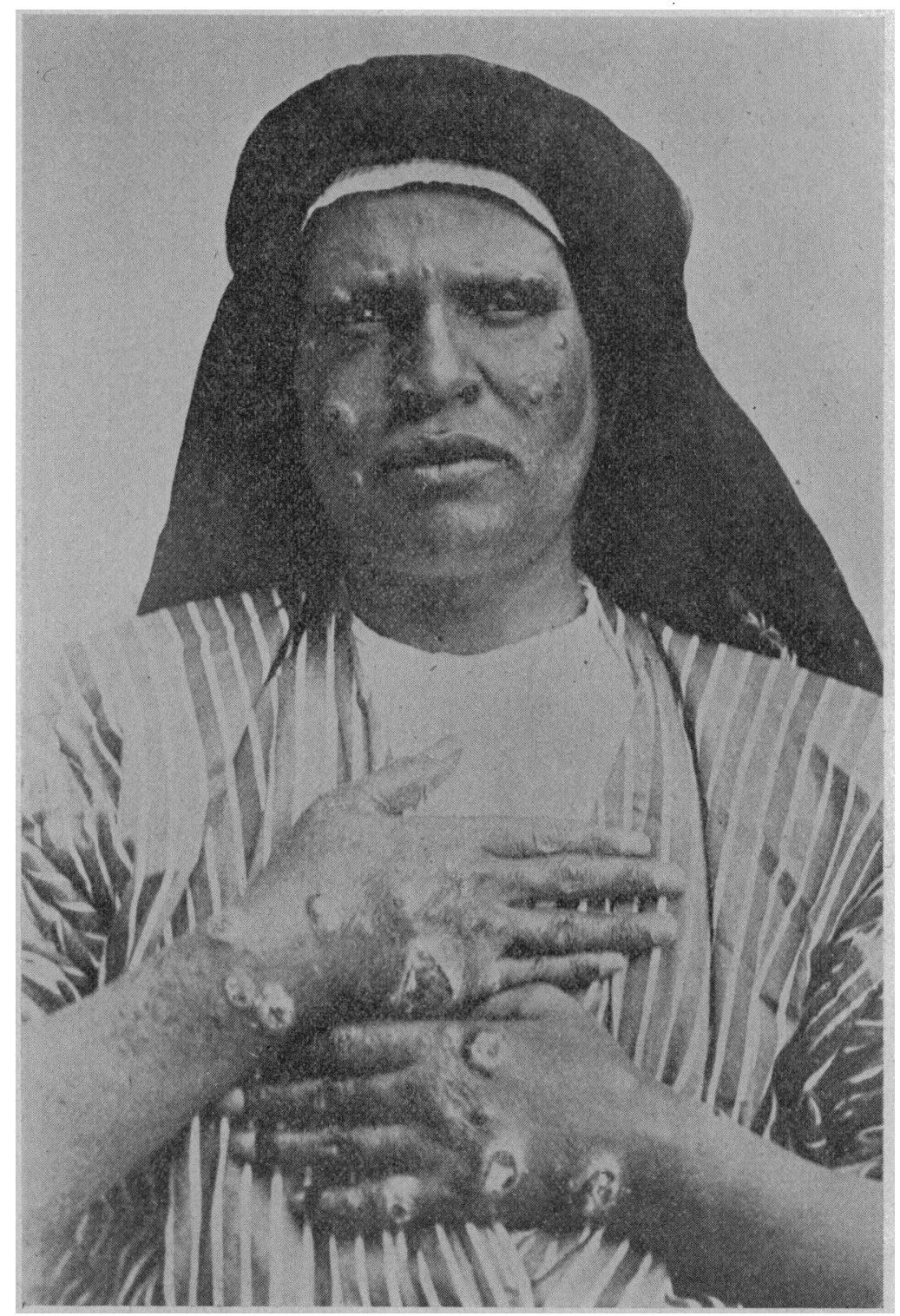

Fig. 12.-Large Nodular Variety of Leprosy of Face a: d Iar co.

taken outside the city walls, along the roadside. It is a woman, 21 years of age, who had the disease a few years previously. The only parts affected were the fingers and hands. The picture demonstrates, most interestingly, the peculiar behavior of leprosy, and shows conclusively Nature's effort in effecting a cure. The right hand has entirely disappeared, while on the left nothing is left but the thumb. It is a case in which the process of the disease has spent itself, and a temporary cure at least has been effected.

Fig. 7 illustrates a leper 22 years of age. His picture
Fig. 9 presents a group of lepers taken along the roadside. Each of these four has a history peculiar to himself. The one on the extreme left lost his hands twenty years ago. The one on the extreme right became totally blind eight years ago. The two in the middle are not so far advanced. In two of these individuals excessive hemorrhages from the nose occurred on several occasions. They are Moslems and residents of the village of Siloam.

Fig. 10 is a case of marked development of leprosy of the face and fingers. The patient is a woman and, 
so far as she remembers, she has had the malady from early childhood. Her age is 25 years. As seen in the illustration, the nose and face bespeak and indicate how destructive the lesions of leprosy may be. 'The invasion of the nose has been great, much of it already having been destroyed. The face is covered with leprous nodules, the integument is infiltrated and thickened, which, in combination with the nasal deformity, constitutes a pitiable spectacle of human suffering. The patient is voiceless, both the soft palate and the larynx being very much damaged. The hands and fingers have suffered. Leprosy existed in the family.
13 the face is characteristic of leprosy and illustrates the small nodular form of the disease.

COMMUNICATION OF LEPROSY.

Respecting the communication of leprosy, the following incident, related to me as being authentic, is rather curious and interesting: A physician living in Bogata, Columbia, S. A., after trying in every way to protect his family against leprosy, was very much astonished and grieved to find his wife in the first stage of the disease. After careful investigation to discover how she contracted the malady, he at last thought of the country woman who furnished the family with eggs.

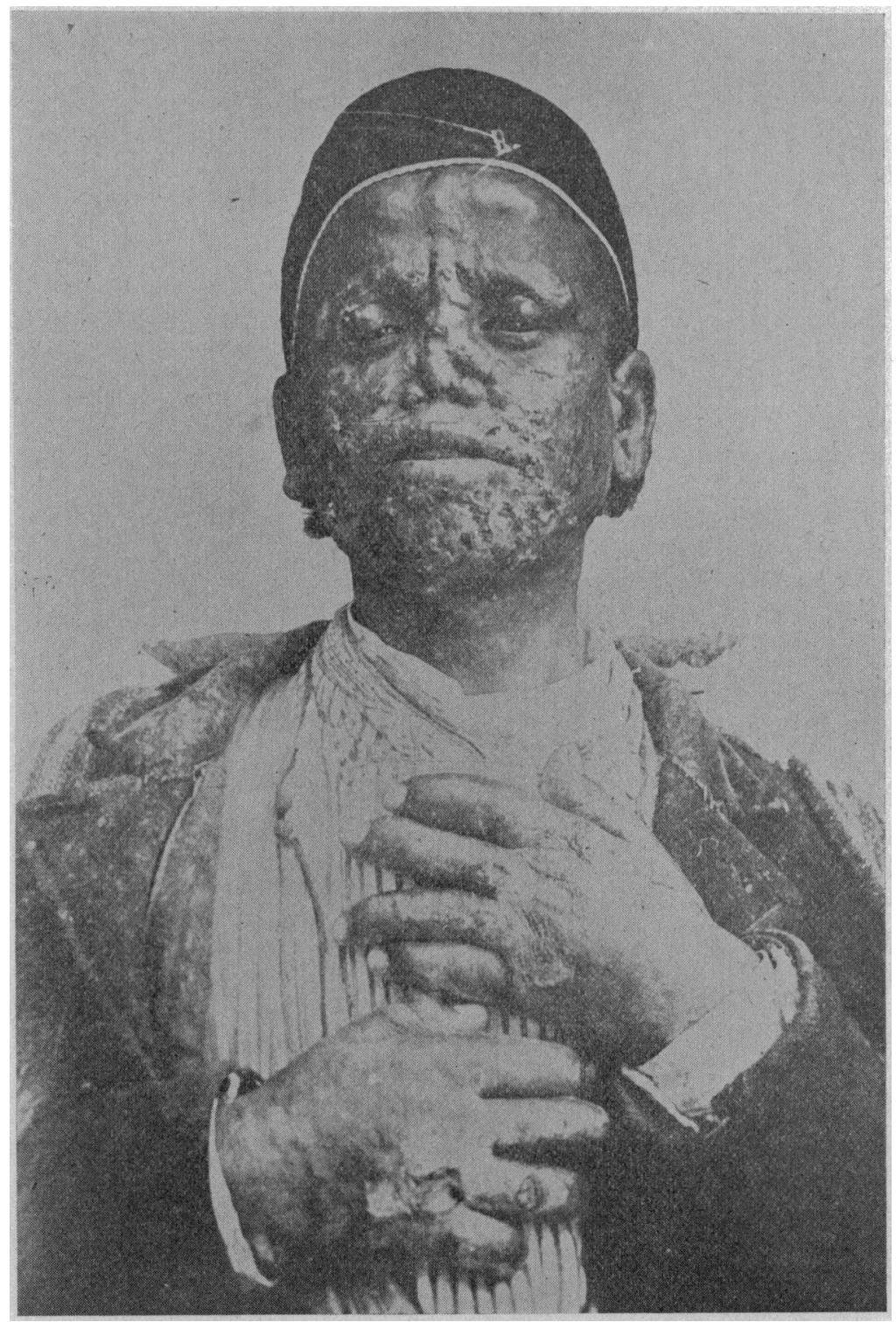

Fig. 13.--Small Nodular Variety of Leprosy of the Face.

Fig. 11 is the picture of a little girl, an inmate of "Jesus Hilfe." The child is 12 years old and has been afflicted for four years. At present there exists a nodular eruption of the arms. In addition to this symptom she suffers from an abnormally enlarged abdomen, which perhaps bears no relationship to the disease in question.

Figs. 12 and 13 are copies of photographs presented to me by the authorities of the hospital. They typically portray the ulcerative form of nodular leprosy. Fig. 12 is interesting. An excellent idea is given of the isolation of the nodules and their degenerated state. In Fig.
Going to her place he insisted upon inspecting the poultry yard. There, in a hole in the sand, was the woman's husband in an advanced stage of leprosy, amusing himself by throwing exfoliations from his body to the chickens, which they devoured greedily. IEPROSY AND TUBERCULOSIS.

Owing to the fact that leprosy and tuberculosis are so nearly allied in many of their characteristics, for purposes of differentiation, I have microscopic slides of the bacilli of the two affections. The leprous specimen was obtained from Dr. Einsler and presents, most charac- 
teristically, the bacilli. I striking resemblance exists between the bacillus of the two diseases. The bacillus of tuberculosis is rather long and somewhat bent; this is not the case with that of leprosy. Some authorities think lepra bacilli stain much easicr than those of tuberculosis, which accounts for the difference; on the other hand, it is claimed this can not be regarded as a distinction. "But the distribution of the bacilli in the tuberculous and leprous tissue is generally so very different, the tubercle bacilli being usually arranged singly, the lepra bacilli always in large quantities in masses and clumps, that a confusion of the two diseases anatomically can only be possible in exceptional cases."

\section{CONJUGAL TUBERCULOSIS. A STUDY OF CASE TO CASE INFECIION.}

\section{H. IT BANNISTER, M.D.}

eilcago.

The notion of the contagiousness of tuberculosis is largely an a priori conception and not based exclusively on clinical evidence. It is only within the past two decades that it has been seriously considered by the medical profession, certainly in most countries, and until Koch's discovery of the tubercle bacillus it was, if held anywhere, at least a quiescent theory. Nowadays no one can reasonably question the fact of its communicability to a certain extent, since there is ample evidence of the fact of its occasional occurrence. 'The question remains, what is the proportionate danger of such occurrence, and does the incidence of phthisis depend so much on direct infection as on constitutional and hereditary predisposition? There is a tendency, of late very manifest, to magnify the former and correspondingly disparage the influcnce of the latter. and the hereditary clement in the causation of the disorder, bids fair to be repudiated by the profession, or in any case to be comparatively neglected. It appears to the writer, therefore, that it might be worth while to collect what data are available to be at least suggestive as regards this question. If we find that ordinary exposure to tuberculosis is not necessarily or as a rule followed by the disease, it would be a fact well worth noting, and if we also find that heredity seems still strongly in evidence, both facts together would go far to reinstate the formerly held notions of etiology of the disease at the expense of the modern notion of its virulent communicability or contagion. There is some authority still for the opinion that direct transmission of the disorder is rare; Sir H. D. Beevor, ${ }^{1}$ in a recent article, concludes from an analysis of the mortality statistics of certain English districts, that the local constancy of phthisis mortality does not indicate the action of such a disturbing factor as case to case infection. He also quotes other authorities who have noticed the same facts, among them Andvord who, from a careful inquiry into the tuberculous mortality of five Swedish towns for ten to sixteen years, concluded that in like places special constancy of lung tuberculosis points to no place among infectious illnesses, a view that Beevor himself endorses.

It seemed to me, therefore, that if some other possibly more direct statistical proof of this view could be had it would be of some value. An inquiry as to the incidence of lung tuberculosis in a class in which any common heredity could be excluded and in which the possibilities of contagion or direct case to case communication of the disease are at a maximum would apparently best furnish facts bearing on the question.

\footnotetext{
1. British Med. Jour., Aug. 18, 1900.
}

If contact or association could cause the spread of pulmonary tuberculosis, there could be no more favorable conditions found for its transmission than the relations of husband and wife. If one of these is affected it would seem that with the popular teaching as to the contagion of consumption, nothing short of absolute immunity could save the other, the more so since we know that in hardly any case, and in none up to recent years, have there been any special precautions against contagion employed. Therefore, a study of the incidence of tuberculosis in married couples would have some value provided the facts were collected under the proper conditions. The first of these is that any series of cases fairly represents the aggregate experience or obscrvations of the narrator. It is easy to collect exceptional facts that impress themselves upon us, but such are of no value in proving rules; what is wanted is a statement of all cases that conform to certain other requircments of the question. These are that: 1 , there should be no question as to the facts, no conjectures as to diagnosis or other points, and 2 , the observation should have been sufficiently prolonged to avoid the possible cluarge of insufficiency and consequent unreliability. It is easy to obtain accounts of apparent infection from husband to wife and vice versa, especially since the discovery of the tuberculosis germ; almost any general practitioner of long experience can report one or two. It is another thing, however. to obtain records of all the cases in one's observation in which one or the other or both have suffered, and to secure at the same time data meeting the above conditions. I have been able to secure thus far the following thirty-two cases, most of them in my own personal acquaintance, and the facts beyond any doubt as regards requirements stated above.

CAsE 1.-B. J., of good family history except that his father died young, probably not of tuberculosis, narried M. C., of considerable neurotic and tuberculous taint. Three sons were born; the oldest died of tuberculosis at the age of 20 ; the father died two years later of the same disease, the mother following him a few weeks later, after having been recognized as consumptive for a longer time than her husband. The youngest son died of tuberculosis nineteen years later, and the second son in an epileptic attack still later.

In all of these cases there was no question as to the diagnosis and it seems probable that the husband was infected by the wife, though there was a history of something like a possible lung traumatism that may have had its influence.

CAse 2.-D. J., the youngest son of B. J. and M. C. (see above), married J. L., whose family history so far as known was good, and died of typical tuberculosis some years later, the exciting cause unknown. 'There were no children. His wife, who nursed him through all his illness, did not contract the disease and after twenty or more years is still living in good health.

CASE 3.T. W. whose mother and one sister were supposed to have died of consumption, married M. F., whose family history is unknown. She has survived him twenty-one years, in rood health. Their children are still living. J. W. died in 1880 , of well-marked. typical pulmonary tuberculosis.

CASE 4.-P. C. C., whose family history was unknown, died of typical pulmonary tuberculosis in 1861 . His wife, H. C. C. never showed any signs of the disease, antd died in 1900 of ailments incident to old age. Five surviving children are all well.

Case 5.-W. F. J., whose family history was dubious as to ancestral tuberculosis, and with some alcoholism in the ancestry, married M. C., whose family history was supposed to be good. He died of tuberculosis, nearly twenty years before his wife, who died of senile decay at about 80 . Of three children, one daughter died of consumption before her father.

CAsE 6.-F. F., whose father died of organic brain disease, married G. F., who died of tuberculosis within two years of her marriage. Her husluand. who was deroted to her, exhibited 